\section{Upper Gastrointestinal Bleeding: A Complication of "Inlet Patch Mucosa" in the Upper Esophagus}

Heterotopic gastric mucosa has been reported along the alimentary tract, and its prevalence in the esophagus varies from $0.1 \%$ to $10 \%$ (1,2). Rare complications have been described. including dysphagia, stricture, esophagotracheal fistula formation, and adenocarcinoma development $(1-3)$.

A 20-year-old male was admitted to our hospital due to two episodes of hematemesis with hypovolemic signs $(98 \mathrm{bpm}$ and blood pressure $100 / 60 \mathrm{mmHg}$ ) and hematocrit of $38 \%$. A complete emergency endoscopic examination showed two ulcers $(1.5 \times 1.0 \mathrm{~cm}$ each) located at a distance of $22 \mathrm{~cm}$ from the incisors (Figure 1). No signs of gastroesophageal reflux and no other possible sources of bleeding were noted in a complete esophagogastroduodenoscopy. The biopsy speeimens taken from the esophageal ulcers showed squamous and foveolar, gastric-type mucosa, lined by surface columnar mucous cells. A mild lymphocytic infiltrate was present in the lamina propria (Figure 2 ). Omeprazole ( $40 \mathrm{mg}$ once daily) was administered, with no recurrence of the hemorrhage in the one-year follow-up. At the control endoscopic examination, a circumferential red patch was detected at $22 \mathrm{~cm}$ from the incisors, but no ulceration was seen.

Heterotopic gastric mucosa is most commonly found in the cervical portion of the esophagus, due to the widespread use of gastrointestinal endoscopy. These lesions appear as a reddish spot or patch that stands out against the pale squamous epithelium of the esophagus. Biopsies of these patches show fundic-type mucosa with chief and parictal cells $(1,2)$. The clinical relevance of these lesions is controversial, and a relationship between the endoscopical finding and symptoms is rarely demonstrable $(3,4)$. Murray et al. describe a case with repeated rectal bleeding because of gastric mucosa present in the rectum. controlled with $\mathrm{H}_{2}$-receptor antagonists (5), but no cases of upper gastrointestinal bleeding due to heterotopic mucosa in the cervical esophagus have been described.

\section{R. Baraller', J. M. Bordas', J. Ordi ', J. Llach', J. I. Elizalde', F. Mondelo \\ Endoscopy Section, Gastrointestinal Service, and \\ 2Department of Pathology, Clinic i Provincial Hospital, \\ University of Barcelona. Barcelona, Spain}

\section{References}

1. Jahbari M, Goresky C.4. Lough J, et al.: The inlet patch: heterotopic gastric mucosa in the upper esophagus. Gastroenterology $1985 ; 89 ; 352-356$.

2. Borhan-Manesh F, Farnum IB: Incidence of heterotopic gastric mucosa in the upper esophagus. Gut 1991: 32: 968-972.

3. Ratmer HM. MCKinley MJ: Heterotopic gastric mucosa of the upper esophagus. Gastroenterology 1986:90: 1309.

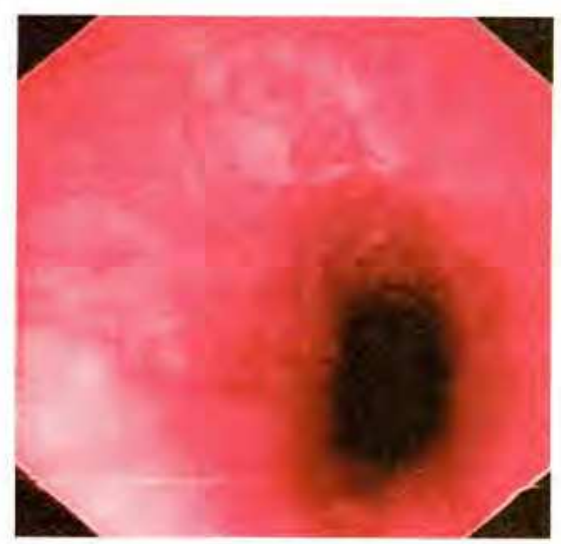

Figure 1: An endoscopic examination of the upper esophagus, showing two circumferential ulcers $(1.5 \times 1.0 \mathrm{~cm}$ each $)$ at a distance of $22 \mathrm{~cm}$ from the incl50 rs.

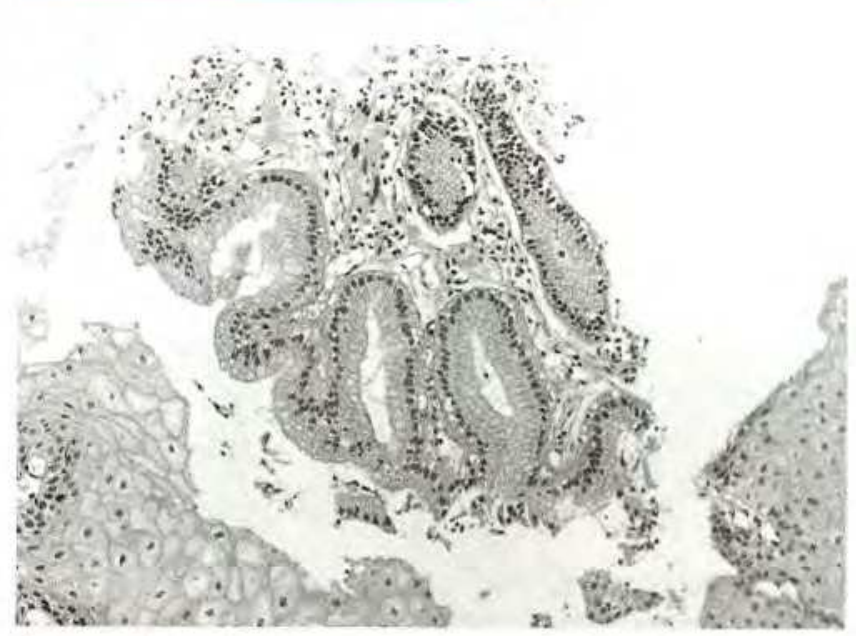

Figure 2: A small fragment of foveolar, gastric-type mucosa lined by sur. face columnar mucous cells. There is a mild lymphocytic infiltrate in the lamina propria. Two fragments of squamous esophagic mucosa are seen at the top (hematoxylin-eosin, original magnification $\times 100$ \}.

4. Payne-James J.J. Loft DE, Mears T. Lovell D: Symptomatic cervical oesophageal ectopic (heterotopic) gastric mucosa treated with omeprazole. Int Med Res 1991; 19: 161-164.

5. Murray FE. Lombarl M, Dervan $P$, et al.: Bleeding from multifocal heterotopic gastric mucosa in the colon controlled by an $\mathrm{H}_{2}$-antagonist. Gut 1988; 20: $848-85 \mathrm{I}$.

Corresponding Author

J. M. Bordas, M.D.

Section of Digestive Endoscopy

Hospital Clínic i Provincial

University of Barcelona

Villarroel 170

08036 Barcelona

Spain 